\title{
Beginning and end of treatment of patients who dropped out of psychoanalytic psychotherapy
}

\author{
Início e fim de tratamento de pacientes \\ que abandonaram a psicoterapia psicanalítica
}

Simone Isabel Jung, ${ }^{1}$ Fernanda Barcellos Serralta, ${ }^{2}$ Maria Lucia Tiellet Nunes, ${ }^{3}$ Cláudio Laks Eizirik ${ }^{4}$

\begin{abstract}
Introduction: Even though it is expected that patients and therapist will agree on when to terminate psychotherapy, quite often patients discontinue treatment on their own. This study aims to better understand dropout in psychoanalytic psychotherapy (PP).

Method: Baseline and post-treatment interviews were conducted with six adult women classified by their therapists as dropout patients at a PP outpatient clinic. Results were analyzed using Bardin's content analysis.

Results: Content analysis generated five categories (reasons for treatment, goals, readiness to change, previous treatment, transference) for the baseline interviews and three categories (change process, results, interruption) for post-treatment interviews. Unclear treatment goals, low readiness to change, early signs of negative transference and resistance, and absence of recognition of their own participation in problems emerged in baseline interviews. In most cases, the patient's evaluation of the therapeutic relationship was not determinant of dropout. Therapeutic gains, dissatisfaction, and resistance during the psychotherapeutic process seemed to be associated with noncompliance.

Conclusions: Decisions to initiate, continue, or quit PP depend on multiple factors, such as initial goals, readiness to change, insight capacity, awareness of personal problems, resistance, and transference. However, these factors should be considered in view of the methodological limitations of this study. Further investigation of PP dropout is still necessary.
\end{abstract}

Keywords: Patient dropout, psychoanalytic psychotherapy, qualitative research, mental health services.

\section{Resumo}

Introdução: Embora se espere que pacientes e terapeuta concordem sobre o momento da alta ou fim do tratamento, a interrupção por conta própria do paciente é bem comum. O objetivo deste estudo é compreender melhor o abandono de tratamento em psicoterapia psicanalítica (PP).

Método: Entrevistas foram conduzidas no início e após o tratamento com seis mulheres adultas classificadas por seus terapeutas como tendo abandonado o tratamento em uma clínica de PP. Os resultados foram analisados utilizando-se o método de análise de conteúdo de Bardin.

Resultados: A análise de conteúdo deu origem a cinco categorias (razões para o tratamento, objetivos, disposição para mudar, tratamento prévio, transferência) nas entrevistas iniciais e três categorias (processo de mudança, resultados, interrupção) nas entrevistas pós-tratamento. Objetivos terapêuticos obscuros, pouca disposição para mudar, sinais de transferência negativa e resistência, e o não reconhecimento da própria participação nos problemas surgiram nas entrevistas iniciais. Na maioria dos casos, a avaliação da paciente sobre a relação terapêutica não foi determinante para o abandono. Ganhos terapêuticos, insatisfação e resistência durante o processo psicoterapêutico pareceram estar associados com a não aderência.

Conclusões: As decisões de iniciar, continuar ou interromper a PP dependem de múltiplos fatores, como objetivos iniciais, disposição para mudar, capacidade de insight, consciência de problemas pessoais, resistência e transferência. No entanto, esses fatores devem ser considerados em vista das limitações metodológicas deste estudo. Mais investigações com foco no abandono da PP são necessários.

Descritores: Abandono de tratamento, psicoterapia psicanalítica, pesquisa qualitativa, serviços de saúde mental.

\footnotetext{
${ }_{1}^{1}$ Psychologist. PhD candidate, Medical Sciences: Psychiatry, Universidade Federal do Rio Grande do Sul (UFRGS), Porto Alegre, RS, Brazil. Professor, Faculdades Integradas de Taquara (FACCAT), Taquara, RS, Brazil. ${ }^{2}$ Psychologist. PhD in Medical Sciences: Psychiatry, UFRGS, Porto Alegre, RS, Brazil. Professor, Universidade do Vale do Rio dos Sinos (UNISINOS), São Leopoldo, RS, Brazil. ${ }^{3}$ Psychologist. PhD, Freie Universität Berlin, Berlin, Germany. Professor, Pontifícia Universidade Católica do Rio Grande do Sul (PUCRS), Porto Alegre, RS, Brazil. ${ }^{4}$ Psychoanalyst. PhD in Medicine. Associate professor, UFRGS, Porto Alegre, RS, Brazil.

This paper is part of the first author's doctoral dissertation project, entitled "Dropout in psychoanalytic psychotherapy: qualitative study," currently under way at the Graduate Program in Medical Sciences: Psychiatry, at Universidade Federal do Rio Grande do Sul (UFRGS), Porto Alegre, RS, Brazil.

Financial support: none.

Submitted Dec 11 2012, accepted for publication Jun 03 2013. No conflicts of interest declared concerning the publication of this article.

Suggested citation: Jung SI, Serralta FB, Nunes ML, Eizirik CL. Beginning and end of treatment of patients who dropped out of psychoanalytic psychotherapy.
} Trends Psychiatry Psychother. 2013;35(3):181-90. 


\section{Introduction}

Even though it is expected that patients and therapist will agree about when to terminate psychotherapy, quite frequently patients discontinue psychotherapy on their own, in many ways and for many reasons. The very definition of this phenomenon is not a consensus, and terms such as premature discontinuation, premature termination, unilateral termination, and dropout are all used, sometimes with different forms of operationalization. So, when studying dropout, one of the problems faced is choosing among the definitions available. Premature termination or dropout can be defined as unilateral treatment termination, i.e., when the patient decides to end psychotherapy contrary to both the therapist's recommendation and the initial agreement made between patient and therapist. Another dropout situation is when the patient starts treatment but discontinues it prior to recovering from the problems that led to treatment, i.e., without meeting the therapeutic goals. ${ }^{1}$

Psychotherapy approaches differ in terms of treatment goals, psychotherapy length, dropout definition, and criteria for success. ${ }^{2}$ Psychoanalytic psychotherapy (PP), for example, is typically directed to the analysis of defenses, transference, and conflicts, aiming to help the patient become aware of them. ${ }^{3}$ Therefore, PP requires from the patient ego strength or resources, the ability to withstand the revival of painful situations, insight capacity, and motivation to explore thoughts, emotions, and current conflicts in order to link them with past situations and thus expand self-knowledge. Except for brief psychodynamic models, PP is considered a long-term insight-oriented therapy that ideally terminates when both patient and therapist agree that the therapeutic goals have been achieved. This criterion clearly involves a good deal of subjectivity of both patient and therapist.

Regardless of the criterion used to define therapy dropout, reports indicate high rates of the phenomenon ${ }^{1,4}$ in different ages, diagnostic groups, and treatment modalities. In a recent meta-analysis, Swift \& Greenberg ${ }^{1}$ reported that one in five patients discontinued therapy. In mental health services in Brazil, dropout rates are comparable to those found in other contexts. ${ }^{5,6}$

These estimates provide grounds for concern, especially when one takes into consideration everything implied in the premature termination of treatment. Most patients who drop out of therapy eventually ask to return, making it necessary to restart the entire process. The psychological, financial, and time investments made fuel the patient's frustration, leading to hopelessness in receiving aid with this type of treatment. ${ }^{7}$ The therapist is not immune to frustration either, especially those less experienced, who may be overwhelmed by feelings of inadequacy and incompetence. Thus, the negative impact of discontinuation is felt by all the parties involved.

Despite many studies investigating psychotherapy dropout, several inconsistencies remain in research findings about this phenomenon. Nevertheless, in most investigations, patients who dropped out of psychotherapy: showed low motivation (in counseling therapy, ${ }^{8}$ cognitive behavioral therapy [CBT], ${ }^{9,10}$ and psychosocial treatment ${ }^{11}$ ); had limited expectations of results (in psychosocial treatment ${ }^{11}$ and $\mathrm{CBT}^{12}$ ); were younger (in different types of therapy ${ }^{1}$ ); presented low socioeconomic and educational levels (in different types of therapy ${ }^{4}$ ); poor therapeutic alliance (in psychosocial treatment, ${ }^{11} \mathrm{CBT}$, and experiential and interpersonal therapies $\left.{ }^{13}\right) ;$ and more resistance to treatment (in $\mathrm{CBT}_{1}{ }^{9,13}$ psychosocial treatment, ${ }^{11}$ and experiential and interpersonal therapies ${ }^{13}$ ).

As psychoanalytically oriented therapists, we believe that the length and depth required for the therapeutic work (of both patient and therapist) in PP may reveal an even greater level of complexity for the issue of psychotherapy dropout. Thus, it is possible that the factors associated with dropout in this therapeutic modality are not the same as those found in other therapies. Looking specifically at studies that have examined PP, we found that patients who discontinued treatment had: less willingness to start psychotherapy ${ }^{14-16}$; a concept of "cure" that diverged from the therapist's ideas ${ }^{17}$; less insight ${ }^{18,19}$ and less psychological mindedness ${ }^{16}$; lower levels of therapeutic alliance 20,21 ; more frequent use of immature defenses, especially narcissistic ones ${ }^{19,22}$; a less dynamic work and less involvement in the exploration of problems ${ }^{20}$; high levels of aggressiveness ${ }^{15,23}$; low selfesteem $^{15,23}$; poor object relations ${ }^{15,16,23}$; deficits in the ability for introspection and in frustration tolerance ${ }^{24}$; and maladaptive personality functioning. ${ }^{25}$

Qualitative studies on PP dropout are rare. For example, searching for articles published in Brazilian journals on the Virtual Health Library (www.bireme.br) and on the Scientific Electronic Library Online (www. scielo.br), only one article was found focusing on dropout in adult individual outpatient PP. In that study, ${ }^{26}$ conducted with six borderline patients, impulsiveness, manipulation, and affective dissociation were prominent in the three cases that dropped out of therapy.

In international journals, searched on PsycINFO (www.apa.org/psycinfo), qualitative investigations are also scarce, even when the search is extended to include studies with children, adolescents, groups, and inpatients. One of these studies, conducted with six adult patients seen at an outpatient clinic, revealed that dropouts sought psychotherapy as part of shopping around for a suitable psychotherapy or wanting to try a particular type of psychotherapy and see if they could 
tolerate it or benefit from it. ${ }^{27}$ In another qualitative study on this topic, the reasons for premature termination of psychotherapy were investigated. Twelve patients, four of which had undergone PP, were interviewed. Results revealed that dropouts who had positive experiences with the termination reported a strong therapeutic alliance and positive psychotherapy results. Psychotherapy ended mainly for logistic or financial reasons, and the feelings aroused in this process were discussed with the therapists. In contrast, dropout patients with negative experiences with the termination reported weaker alliance and mixed results. In these cases, psychotherapy generally ended abruptly, and its end was rarely discussed or planned in advance with therapists. ${ }^{28}$

Studies evaluating treatment termination in PP may shed light on the understanding of dropout. For example, in two studies, 22 cases of termination were interviewed with a focus on what was useful and what hindered PP. According to the therapists' point of view, factors relevant for therapeutic success included the development of a close, safe, confident relationship with patients, based on genuine interest in their problem, technical flexibility, and non-retaliation to criticism. ${ }^{29}$ According to the patients' perspective, therapeutic success was due to their felling of having a special place to talk about themselves and to have new experiences, as well as mutual collaboration while exploring conflicts. ${ }^{30}$ In contrast, patients' difficulties in talking about themselves, not receiving help to solve practical problems, therapist passivity, a feeling that something was "missing" in treatment, ${ }^{30}$ and fear of having a close relationship with the therapist ${ }^{29}$ were seen as factors that hinder PP.

Treatment dropout still needs to be better explained, especially in PP, which is much less studied than other modalities. ${ }^{31}$ Specifically, a regional issue must be taken into account: in Brazil, PP is generally practiced without much concern with measuring processes or results. Usually, therapists are very reluctant to use any type of register apart from the traditional "dialogued interviews," i.e., transcripts of the dialog held between patient and therapist, recorded by the therapist (by memory), after each session. This culture is obviously not very friendly to research and imposes many methodological difficulties to empirical investigation in psychotherapy. Moreover, studies on dropout in Brazil are generally conducted at university services, with therapists that are not yet licensed, i.e., undergraduates under clinical training.

Therefore, in order to better understand factors associated with the unilateral termination of $\mathrm{PP}$, this study analyzed the beginning and end of treatment of patients seen at a PP outpatient clinic and considered as dropouts by their therapists (licensed professionals of psychology and medicine).

\section{Methods}

This was a naturalistic, qualitative study. It was approved by the Research Ethics Committee of Universidade Federal do Rio Grande do Sul (UFRGS), Porto Alegre, RS, Brazil (protocol no. 20035). All participants signed an informed consent form prior to being included in the study.

Participants were six women (here referred as P1, P2, P3, P4, P5, and P6) treated by therapists of the same sex, randomly selected from a database of 29 patients that had interrupted PP at an outpatient clinic located in southern Brazil that trains health professionals in PP at the graduate level. This database was created to study outcomes in PP and included 34 adult patients of both sexes who had attended at least 18 sessions of psychotherapy. Of these, five patients completed therapy and 29 dropped out of treatment at some point after the first 18 sessions. In both groups, the invitation to participate in the study was made by regular mail, followed by a phone call, at least 6 months after the end of treatment (after either completion or dropout). The 6 months elapsed between the end of psychotherapy and the interviews were planned to allow sufficient time for patients to process and reflect on what had occurred in treatment. Other details of the original database can be obtained elsewhere. ${ }^{32}$ In this study, describing a subsample of six dropout cases, treatment length ranged from 7 to 18 months (mean \pm standard deviation $=12.8 \pm 4.62$ ). Because the database did not include cases with less than 18 sessions attended, all cases here analyzed can be considered late dropouts.

The number of participants was defined by saturation, ${ }^{33}$ i.e., the inclusion of new participants was suspended when the data began to show redundancy or repetition. Participants were adults with a mean age of $29.8 \pm 5.71$ years. Five patients were single and three had higher education degrees (the other three had high school degrees). Socioeconomic level was medium to low.

Psychotherapists were licensed professionals of psychology $(n=5)$ and medicine $(n=1)$ with a mean age of $32.2 \pm 10.3$ years. All were trainees in PP, with 1 to 5 years of psychotherapy experience at the time (mean $=2.83 \pm 3.06$ ).

Psychotherapy was insight-oriented, face to face, nonmanualized, delivered twice a week in two cases and weekly in the other four. Data were collected using two interviews. The first one was the archived baseline interview, conducted by the patient's therapist as usual. This is an open-ended interview subsequently recorded by memory (dialogued interview), as usually seen in PP treatments in our context. The other interview was a posttreatment interview held at the same institution where 
treatment was conducted, on average 19 months after psychotherapy. This second interview was carried out by the first author and lasted for approximately 45 minutes. It was recorded in audio and subsequently transcribed. Post-treatment interviews were semi-structured and sought information about the end of treatment, the reasons for interruption, the relationship with the therapist, and the results obtained with psychotherapy.

All interviews were analyzed using Bardin's content analysis, ${ }^{34}$ as follows: 1 ) the first author read all interviews in detail; 2) registration units (RUs), i.e., significant fragments of the patients' discourse, were selected; 3 ) RUs covering similar topics were grouped, generating categories (to increase methodological reliability, two independent examiners evaluated the pertinence of RUs in each category); 4) data interpretation.

\section{Results}

The corpus of baseline interviews amounted to 43 pages and generated five categories and 13 subcategories, as shown in Table 1.

Category A. Reason for treatment. The reasons that led the participants of this study to seek PP were grouped into three subcategories: problems in interpersonal relationships, complaints concerning the depression spectrum, and difficulties with impulse control. All patients reported interpersonal problems (subcategory A.1), especially with romantic partners and family of origin ("I live with my boyfriend, but we just fight... and now it's very bad, that's when I decided to come" [P1]). Participants also mentioned depressionlike symptoms (subcategory A.2), such as sadness, loneliness, low self-esteem, and emptiness ("I have no desire for anything, life has gone stale for me, nothing else matters, only my son" [P2]). Another reason for seeking psychotherapy was impulse control difficulties (subcategory A.3: "I was angry, lost control... I just lost it" [P3]).

Category B. Goals. We found that all therapists directly questioned what were the goals and expectations of the patient with therapy. This category includes all answers given to this question. Comments were addressed in varied aspects and grouped into the following subcategories: past issues, support and guidance, and internal changes.

Patients sought psychotherapy to resolve past issues (subcategory B.1), e.g., to forget painful events and to avoid repeating the story of parents ("I want to forget, to live from now on, erase my memory of this scar, I am very hurt" [P2]). They also sought psychotherapy to speak and to receive support and guidance (subcategory B.2: "I think I'll come here once a week, I'll talk to you and you will give me your professional opinion" [P3]). Patients also mentioned seeking psychotherapy to make internal changes (subcategory B.3), e.g., know themselves, enhance femininity and self-esteem, develop the capacity to be alone, control impulses, and gain self-knowledge ("I want to regain that glow, you know, to take care of myself, to like myself" [P2]). Only P3 mentioned the expectation of gaining self-understanding ("I want to find myself, to get to know me... I want to learn to know myself").

Category C. Readiness to change. This category includes all the participants' statements regarding their readiness to change, with the subcategories insight, resistance, and referral. Participants showed some insight of their psychological condition (subcategory C.1), somehow recognizing their suffering and need of treatment ("I cannot

Table 1 - Baseline interview categories

\begin{tabular}{ll}
\hline Categories & Subcategories \\
\hline Category A (reason for treatment) & A.1 Interpersonal \\
& A.2 Depression \\
A.3 Impulse control & B.1 Past issues \\
Category B (goals) & B.2 Support and guidance \\
& B.3 Internal changes \\
Category C (readiness to change) & C.1 Insight \\
& C.2 Resistance \\
Category D (prior treatment) & C.3 Referral \\
Category E (transference) & D.1 Evaluation of goals \\
& D.2 Prior psychotherapist \\
& E.1 Positive transference \\
& E.2 Negative transference \\
\hline
\end{tabular}

184 - Trends Psychiatry Psychother. 2013;35(3) 
stand these things in my life... I saw that alone I'm not able to carry on" [P1]). Furthermore, P1 and P5 recognized their participation in the issues presented ("I also do not want to be only complaining about my parents... I have to resolve what is not right with me" [P5]).

Early manifestations of overt resistance (subcategory C.2) were found in various fragments of speech ("I do not really want to come, I was very reluctant. Yesterday I even thought about calling to cancel. I spoke with a friend and said that I would not go, then she asked what was the excuse and that's exactly it, an excuse" [P1]).

Finally, dropout patients also mentioned that the therapeutic treatment had been recommended by friends, relatives, or health professionals (subcategory C.3: "My colleagues talked to me and told me that I needed help" [P6]).

Category D. Prior treatment. Four participants had undergone previous psychological treatment. They gave their opinions and evaluations concerning that treatment (subcategory D1) and therapist (subcategory D.2).

Patients mentioned partial improvements in the problems that led them to seek psychotherapy. However, a negative effect of prior psychotherapy was also referred (subcategory D.1: "I already underwent treatment before, nothing changed; I think things even got worse" [P2]). As per the relationship with the previous therapist (subcategory D.2), P4 reported discrepancies between her expectations and the therapist's attitudes ("I expected her to tell me what I had to do and she only listened to me").

Category E. Transference. This category includes all manifestations of transference found in the baseline interviews. The category was subdivided into positive transference (subcategory E.1), including libidinal impulses and their derivatives, especially affectionate and friendly feelings, and negative transference (subcategory E.2), with a predominance of aggressive drives and their derivatives, e.g., envy, jealousy, idealization, among others. Positive transference manifestations were identified ("Yes I will come back, I liked you a lot" [P2]), but negative transference manifestations (subcategory E.2) were much more evident ("I'll tell you more when I feel more comfortable" [P4]). P2 and P3 presented both positive and negative transference manifestations, the latter ones mainly in the form of idealization.

Data in the post-treatment interviews amounted to 92 pages that generated three categories and seven subcategories, as shown in Table 2.

Category F. Change Process. This category includes patients' general remarks about the process of change occurring during psychotherapy. Three subcategories provide an understanding of the process of change: insight, therapeutic relationship, and resistance.

Patients reported developing a new understanding of their difficulties during psychotherapy (subcategory F.1: "There I reflected and went within me, and I could see... I had really understood what was hindering" [P2]). The ability to work on psychological issues on their own was addressed by P2 and P3 ("I can now evaluate myself by myself, when something is happening I remember the sessions" [P3]).

The participants described the negative and positive aspects experienced in the relationship with their therapists (subcategory F.2). Patients (except P4) reported positive aspects of the therapeutic relationship (e.g., learning with the therapist) ("It was very nice, we had an affinity that was great... well, relationship with her was very good" [P3]). P4 defined her relationship with the therapist as consisting of criticism and nonunderstanding ("There was a negative side... depending on how it is said, it can be shocking to the patient... all of a sudden the patient does not accept this").

Resistance (subcategory F.3) became evident in all patients. These manifestations included perceiving psychotherapy as a sacrifice, as an ordeal, or as a waste of time ("I missed various sessions; I felt it was an ordeal to go there... I have two sides, the need to go and the desire to stay at home, so that I will not have to show what is inside of me" [P1]; "There were those days you just did not want to go, which is the resistance itself... we have a very high resistance to treatment, we must be careful, because if not, we will escape... when you're being poked... it is poking the wound, because in the treatment you will actually get to know you better and sometimes you do not want to know you better" [P3]).

Table 2 - Post-treatment interview categories

\begin{tabular}{ll}
\hline Categories & Subcategories \\
\hline Category F (change process) & F.1 Insight \\
& F.2 Therapeutic relationship \\
& F.3 Resistance \\
Category G (results) & G.1 Overall satisfaction \\
Category H (interruption) & G.2 Specific benefits \\
& H.1 Reasons \\
& H.2 Process termination \\
\hline
\end{tabular}


Category G. Results. This category bears all comments made by participants concerning their personal evaluation of psychotherapy results. The evaluation encompassed satisfaction with treatment goals and expectations (subcategory G.1) and specific benefits obtained or not (subcategory G.2).

Participants expressed satisfaction with treatment results and recognition of the help received (subcategory G.1), partially achieving their goals, except for P6, who mentioned being a $100 \%$ satisfied with therapeutic gains ("I think I was able to improve a lot, not resolve, but greatly improve" [P3]).

Moreover, the interviewees described diverse benefits associated with psychotherapy (subcategory G.2). After treatment, they found they were more mature, secure, confident, spontaneous, less impulsive, and less depressive, in addition to improvements in interpersonal relationships. It is noteworthy, however, that some of these benefits were perceived as partial ("I can already hold myself back more often... I was very impulsive" [P3]). Participants also mentioned having obtained benefits in both their professional life and physical health, attributing these changes to the therapeutic experience.

Category H. Interruption. All comments addressing psychotherapy interruption were included in this category, including the reasons for termination (subcategory $\mathrm{H} .1$ ) and the way in which the process was carried out (subcategory H.2).

Several reasons (subcategory H.1) were associated with psychotherapy interruption, e.g., dissatisfaction with the therapist or the psychotherapy, improvements, and resistance. Coded as resistance in this investigation, financial issues were brought up by $\mathrm{P} 1$ and $\mathrm{P} 3$. Resistance was the most evident reason for PP discontinuation ("I was unemployed, had this great excuse so to speak..." [P1]). Conversely, P2 and P6 stated that they decided to discontinue psychotherapy because they were feeling well. Dissatisfaction was referred by P4 and P5 as a reason for termination.

Finally, we found that most participants underwent a final session (subcategory H.2) with their therapists in which the reasons for dropping out were mentioned ("I explained why I was leaving the sessions and she understood me, told me to be happy, for me to try, she said that she would be available if I ever wanted to return" [P6]). The exception was P4, who did not explain the real reason for interruption, because she did not feel comfortable to do so.

\section{Discussion}

In this study, the most common complaints that led the participants to seek psychotherapy (category A) were interpersonal problems, especially difficulties in relationships with partner and family, and depressive symptoms. These motives are similar to those found in other investigations. ${ }^{35,36}$

What the patient wants and expects from treatment has been considered as an important indicator of therapeutic results, regardless of the theoretical approach of psychotherapy. ${ }^{12,37}$ Goals and expectations in psychotherapy can have varying origins: magical or realistic, positive or negative, great or even nonexistent. ${ }^{38,39}$ We observed that the goals of most dropout patients (category B) were specific and magical (e.g., "erase my memory of this scar..." [P2], "you will give me your opinion" [P3]). Only one of them mentioned the expectation of gaining self-understanding, one of the main goals of PP. For PP to be successful, patients should aim not only for specific objectives, but also broad ones, such as enhancing mental abilities and self-awareness. ${ }^{19}$ Thus, specific goals, especially those associated with the desire to make magical changes, may be a sign of low commitment to PP.

It is striking that, even though complaints associated with interpersonal relationships were the main reason for seeking treatment, when questioned by therapists, patients did not mention goals and expectations in this area. This controversial finding may suggest that treatment goals and expectations were unclear for these patients. Another hypothesis is that these patients may have depressive features (see reason for treatment), which could lead them to have low expectations of themselves, and consequently of the treatment. Depressed patients are more doubtful about their therapy and require a higher degree of persuasion at the beginning of treatment. Only after believing that the treatment can bring change will they be able to effectively engage in it. ${ }^{12}$

The contents of baseline interviews revealed information about the patients' readiness to change (category C). Readiness to change was related to the patient's insight capacity (subcategory C.1) about their emotional condition, i.e., the recognition that one is afflicted with a mental illness or problems of an emotional nature for which one can seek solutions. ${ }^{40}$ Studies have shown that successful results in psychotherapy depend on the patient's acceptance of their own involvement in the difficulties that have led to treatment, ${ }^{41}$ and that changes depend mostly of their own effort. ${ }^{42,43}$ In general, respondents admitted psychological distress, but only P1 and P5 acknowledged their involvement in the problems presented. This may be one of the factors explaining the subsequent dropout.

Participants came to psychotherapy as a result of the recommendation of others, and not based solely on their 
own will (subcategory C.3). Furthermore, significant resistance to psychotherapy was observed in baseline interviews (subcategory C.2). This calls us to reflect on the ambivalence of the patients' messages and concealed resistance to treatment. In order for PP to provide an effective improvement, genuine motivation to undertake a process of change is indispensable, ${ }^{18,19}$ which does not seem to be present in the first sessions of the patients interviewed.

The termination of treatment, especially in PP, is often characterized by a later return to treatment. ${ }^{44}$ Four of the patients interviewed had previously undergone PP without reaching their goals (category D), which could be indicative of a greater likelihood of dropout. One of the participants also revealed a negative effect of previous psychotherapy, denoting a mismatch that could be repeated in the new treatment. This would be one aspect to clarify with the patient in the initial phase of psychotherapy, as a way to anticipate this possible repetition.

Aspects of transference, both positive and negative (category E), were evidenced in the first interview. Positive transference promotes and supports the early development of therapeutic alliance. Conversely, early negative transference may interfere with the alliance. ${ }^{45}$ Our participants presented more evidence of negative transference than of positive transference, which may have hindered the development of therapeutic alliance in early psychotherapy. Early negative transference manifestations are certainly a warning that the therapist should be aware of, so as to deal with them in psychotherapy. Negative transference in the form of idealization can be difficult to handle at the beginning of psychotherapy. Even though it may be necessary for the patient to begin treatment, idealization usually hides aggressive drives and wishes of manipulation and control. Early interpretation of the unconscious meaning of this type of transference can lead the patient to a deep feeling of helplessness, ${ }^{46}$ and consequently, to treatment dropout.

In post-treatment interviews, the participants revealed the development, at varying levels, of an understanding of their difficulties (subcategory F.1) during psychotherapy. However, the ability to work by oneself, cited as an important factor for the successful completion of treatment, ${ }^{47}$ was presented only by $\mathrm{P} 2$ and $\mathrm{P} 3$.

Even though all participants discontinued their treatment, qualitative differences were observed in the relationships held with therapists (subcategory F.2). For example, one patient made several comments suggesting lack of harmony and rapport with her therapist as a major characteristic of the entire psychotherapy. Other participants, in turn, made many positive comments on their therapeutic relationship. Therefore, our results do not support findings that indicate that therapeutic alliance is weaker in dropouts. ${ }^{11,13,20,21}$ Rather, as also pointed out by Tyron \& Kane, ${ }^{48}$ the therapeutic alliance assessed by the patient dropping out was similar to that described by patients who complete psychotherapy.

Resistance appeared in the post-treatment interviews of all patients (subcategory F.3). As Freud postulated, ${ }^{49}$ resistance accompanies the treatment step by step ( $p$. 138). However, participants showed little willingness to overcome resistance, being defensive about possible changes and trying to maintain the status of the disorder. Even though we have no data to assess how the therapists worked patient resistance, we can assume that difficulties in this work may have contributed to dropout. Resistance is no longer seen only as an obstacle to be removed: it is a way the patients have to reveal how their previous experiences influence their behavior here/ now. ${ }^{50}$ So, helping patients understand their resistance is an essential task of therapists in PP. ${ }^{3}$

With regard to therapeutic results, all patients showed overall satisfaction with treatment (subcategory G.1); even though they stopped psychotherapy, most of them partially achieved their goals and expectations. One patient revealed that all her goals were achieved when she interrupted psychotherapy, which may reflect a symptomatic improvement that contributes to premature termination of psychotherapy. Patients may understand that they no longer need professional help because what has been reached so far corresponds to their expectations and their sense of well-being. ${ }^{51}$

Specific benefits from psychotherapy (subcategory G.2) were also mentioned by participants, although some reported having obtained only partial benefits. Additionally, patients sought treatment for a specific reason and eventually improved other areas of their lives, a result also found in other studies. ${ }^{47,52}$ In general, patients were satisfied with treatment results, in spite of its presumed premature termination. Therapists tend to seek broad and substantial improvements for their patients, even when the patient's own goals have been reached. This is the same as saying that the number of cases considered ready for termination is often underestimated by therapists. 32,52 Divergences in what patients and what therapists consider as cure are associated with dropout in PP. ${ }^{17}$ In this respect, it is necessary to highlight that the therapists treating our cases were inexperienced, which may have led them to have perfectionistic expectations more easily, e.g., aspiring to a transference resolution that is not compatible with the patient's reality. One could even consider errors of countertransference, when a therapist fails to support termination due to their own personal ambitions, in most cases much greater than the patient's ambitions. ${ }^{44}$ 
Another consideration is the possibility that our participants may represent a subgroup of patients who achieved the best results among those who dropped out of treatment. In this case, patients who were not found or who refused to participate (see details in Jung et al. ${ }^{32}$ ) could be the ones for whom treatment failed. It is also important to note that in the post-treatment interview, participants developed a friendly relationship with the investigator, which may have favored the manifestation of the positive aspects of treatment rather than the negative ones.

Even though the number of patients who leave treatment without giving a reason for premature termination tends to be significant, ${ }^{53,54}$ in this study only P4 did not expose, in the post-treatment interview, her reason for dropping out (subcategory H.1). In a recent publication on reasons for psychotherapy termination, Westmacott \& Hunsley ${ }^{55}$ found that the motive most often reported by patients was that they were feeling better. The percentage of patients who terminate treatment for being satisfied with its results ranges from $14 \%{ }^{54}$ to $43.4 \%{ }^{55}$ and even $45 \% .^{56}$ In our sample, feeling well and wanting to enjoy the improvements achieved was mentioned as the reason for termination by P2 and P6. In another study conducted in Brazil, Vargas \& Nunes ${ }^{57}$ found that when patients are asked to reveal the reason for dropping out of treatment, they tend to report financial difficulties. Studies in other countries have also emphasized the financial issue, however not as the main motivation. ${ }^{55,56}$ Our data suggest that resistance was main reason for dropping out of therapy.

It is also known that many patients decide to terminate psychotherapy because they are not satisfied with the therapist or the psychotherapy. ${ }^{55,56}$ In our study, dissatisfaction was referred by P4 and P5 as motives to termination. Psychotherapy dropout may occur when the patient is not prepared to respond to the therapist's interventions, which reactivate negative feelings involving the repetition of a previously experienced event. ${ }^{58}$

\section{Conclusion}

The baseline interview is a crucial moment in psychotherapy, especially because it can offer a basis to forecast the future of the therapeutic relationship. ${ }^{46,59}$ In our study, unclear treatment goals, low readiness to change, a limited recognition of the patients' participation in their own problems, as well as premature signs of negative transference and resistance were prominent in the initial sessions of all dropout PP patients. As psychotherapists, we acknowledge that these patient characteristics can also be found in completers. Defining the extent to which these characteristics are more intense in patients who drop out of psychotherapy lies beyond the scope of this study. Also, we should bear in mind that patient characteristics are not isolated features. Competent therapists presumably will help patients overcome resistance and develop psychological mindedness. Moreover, it is assumed that therapists will perform an exhaustive examination of the patient's expectations, motivations, and objectives, and try to establish goals together with them, which could prevent the intensification of negative transference and resistance, and consequently, the discontinuation of psychotherapy. In order to clarify the possible association between patient and therapist factors in PP dropout, we strongly suggest further studies, including the analysis of transcripts or videos of patient-therapist interactions.

Data from our interviews also suggest that dropouts are very ambivalent about PP. Following Freud, ${ }^{60}$ we can infer that interruption may occur in association with the therapist's misperception of the indication of PP. Finding a way of transforming magic into realistic goals, more coherent with the problems that led to psychotherapy, seems to be the major challenge faced by therapists of patients with less insight and who seek more focused changes. It is known that therapist abilities, for example their technical flexibility, are associated with positive results in different psychotherapies. ${ }^{61,62}$ Our data did not include therapist characteristics, so it was not possible to assess whether there was an association between rigid adherence to the psychoanalytic psychotherapy model by the psychotherapists and the patients' decision to interrupt treatment. However, this is a hypothesis that could be analyzed in future investigations. Nevertheless, based on the present results, we recommend that therapists pay more attention to the patients' psychological characteristics and to their expectations with psychotherapy in order to adjust the therapeutic plan. This could possibly prevent psychotherapy dropout.

It is noteworthy that all participants, despite having dropped out of psychotherapy, mentioned positive overall results, specific benefits, partial achievement of goals and expectations, and improvements in areas of life that they had not planned to change. This reinforces the idea that patients, even those who drop out of psychotherapy, may obtain several benefits with psychotherapy, and that the quality of the results is unique to each patient.

Post-treatment interviews showed that therapeutic gains, dissatisfaction, and resistance all seemed to be associated with dropout. However, in most cases, the patient's evaluation of the therapeutic relationship was not determinant of dropout.

This study offers some hypotheses or explanations for the complex phenomenon of dropout in PP. Overall, 
it suggests that the decision to start, continue, or stop psychotherapy depend on multiple factors, e.g., initial goals, readiness to change, insight capacity, recognition of one's own problems, resistance, and transference. These explanations should, however, be considered in view of the methodological limitations of this study. First of all, this was a naturalistic study. Even though naturalistic studies are a useful complement to controlled trials (especially by better representing what is effectively done in clinical practice), they have limited accuracy. Moreover, we used baseline interviews transcribed from memory by the therapists. Even though this kind of record is consistent with the usual practices of PP, it offers less reliability than audio/video recordings. Finally, the long time elapsed between the end of treatment and posttreatment interviews may have generated a recall bias.

The fact that therapists were trainees in PP is another limitation. However, we could argue that this in fact increases the technical validity of the study, considering that training psychotherapists are under systematic supervision and receiving rigorous theoretical and technical guidance. It is worth mentioning that in most psychoanalytic investigations conducted in Brazil, therapists are psychology undergraduates or licensed PP under training, i.e., students or professionals with little experience in conducting therapy. Indeed, the time has come for experienced psychoanalytic therapists to set aside skepticism and the vision that research interferes negatively with the psychotherapeutic process. There is no doubt that combining the intersubjectivity of the psychoanalytic process with the objectivity of scientific research can be very difficult; notwithstanding, seeing it as an obstacle, ignoring the scientific development of the field, and continuing "comfortably protected" behind fantasy and resistance is no longer an option. ${ }^{63}$ Diminishing the distance between therapists and investigators is a challenge for both.

In view of the strengths and weaknesses of this investigation, we recognize that additional research on dropout in PP is still needed.

\section{References}

1. Swift JK, Greenberg RG. Premature discontinuation in adult psychotherapy: a meta-analysis. J Consult Clin Psychol. 2012;80:547-59.

2. Ogrodniczuk JS, Joyce AS, Piper WE. Strategies for reducing patient-initiated premature termination of psychotherapy. Harv Rev Psychiatry. 2005;13:57-70.

3. Gabbard GO. Principais modalidades psicanalítica/psicodinâmica. In: Gabbard GO, Beck JS, Holmes J, editores. Compêndio de psicoterapia de Oxford. Porto Alegre: ArtMed; 2007. p. 14-29.

4. Wierzbicki M, Perarik G. A meta-analysis of psychotherapy dropout. Prof Psychol Res Pr. 1993;24:190-5.
5. Lhullier A, Nunes ML, Horta B. Preditores de abandono de psicoterapia em pacientes de clínica-escola. In: Silvares E, organizador. Atendimento psicológico em clínicas escola. Campinas: Alínea; 2006. p. 229-56.

6. Maravieski S, Serralta FB. Características clínicas e sociodemográficas da clientela atendida em uma clínicaescola de psicologia. Temas Psicol. 2011;19:481-90.

7. Kazdin A. Dropping out of child psychotherapy: issues for research and implications for practice. Clin Child Psychol Psychiatry. 1996;1:133-56.

8. Darker C, Sweeney B, El Hassan H, Kelly A, O'Connor S, Smyth $B$, et al. Non-attendance at counselling therapy in cocaine-using methadone-maintained patients: lessons learnt from an abandoned randomised controlled trial. Ir J Med Sci. 2012;181:483-9.

9. Taylor S, Abramowitz JS, McKay D. Non-adherence and nonresponse in the treatment of anxiety disorders. J Anxiety Disord. 2012;26:583-9.

10. Malerbi, FK, Savoia, MG, Bernik MA. Aderência ao tratamento em fóbicos sociais: um estudo qualitativo. Rev Bras Ter Comport Cogn. 2000;2:147-55.

11. Martino F, Menchetti M, Pozzi E, Berardi D. Predictors of dropout among personality disorders in a specialist outpatients psychosocial treatment: a preliminary study. Psychiatry Clin Neurosci. 2012;66:180-6.

12. Meyer B, Pilkonis PA, Krupnick JL, Egan MK, Simmens SJ, Sotsky SM. Treatment expectancies, patient alliance and outcome: further analyses from the National Institute of Mental Health Treatment of Depression Collaborative Research Program. J Consult Clin Psychol. 2002;70:1051-5.

13. Westmacott R, Hunsley J, Best M, Rumstein-McKean O, Schindler D. Client and therapist views of contextual factors related to termination from psychotherapy: a comparison between unilateral and mutual terminators. Psychother Res. 2010;20:423-35.

14. Charnas JW, Hilsenroth MJ, Zodan J, Blais MA. Should I stay or should I go? Personality Assessment Inventory and Rorschach indices of early withdrawal from psychotherapy. Psychotherapy (Chic). 2010;47:484-99.

15. Ackerman SJ, Hilsenroth MJ, Clemence AJ, Weatherill $\mathrm{R}$, Fowler JC. The effects of social cognition and object representation on psychotherapy continuation. Bull Menninger Clin. 2005;64:386-408.

16. Valback K. Suitability for psychoanalytic psychotherapy: a review. Acta Psychiatr Scand. 2004;109:164-78.

17. Philips $B$, Wennberg $P$, Werbart $A$. Ideas of cure as a predictor of premature termination, early alliance and outcome in psychoanalytic psychotherapy. Psychol Psychother. 2007;80:229-45.

18. Hoglend P, Engelstad V, Sorbye O, Heyerdahl O, Amlo S. The role of insight in exploratory psychodynamic psychotherapy. $\mathrm{Br}$ J Med Psychol. 1994;67:305-17.

19. Hauck S, Kruel L, Sordi A, Sbardellotto G, Cervieri C, Moschetti $L$, et al. Fatores associados a abandono precoce do tratamento em psicoterapia de orientação analítica. Rev Psiquiatr Rio Gd Sul. 2007;29:265-73.

20. Piper W, Joyce A, Rosie J, Ogrodniczuk J, McCallum M, O'Kelly J, et al. Prediction of dropping out in time-limited, interpretive individual psychotherapy. Psychotherapy (Chic). 1999;36:114-22.

21. Tryon GS, Kane AS. Client involvement, working alliance, and type of therapy termination. Psychother Res. 1995;5:189-98.

22. Junkert-Tress B, Tress W, Hildenbrand G, Hildenbrand B, Windgassen F, Schmitz N, et al. Der Behandlungsabbruch: ein multifaktorielles Geschehen. Psychother Psych Med. 2000;50:351-65.

23. Hilsenroth M, Handler L, Toman K, Padawer J. Rorschach and MMPI-2 Indices of early psychotherapy termination. J Consult Clin Psychol. 1995;63:956-65. 
24. Frayn DH. Assessment factors associated with premature psychotherapy termination. Am J Psychother. 1992;46:250-61.

25. Ingenhoven $\mathrm{TJ}$, Duivenvoorden $\mathrm{HJ}$, Passchier J, van den Brink W. Treatment duration and premature termination of psychotherapy in personality disorders: predictive performance of psychodynamic personality functioning. ] Psychiatr Pract. 2012;18:172-86.

26. Tanesi PH, Yazigi L, Fiore ML, Pitta JC. Adesão ao tratamento clínico no transtorno de personalidade borderline. Estud Psicol. 2007;12:71-8.

27. Wilson M, Sperlinger D. Dropping out or dropping in? A reexamination of the concept of dropouts using qualitative methodology. Psychoanal Psychother. 2004;18:220-37.

28. Knox S, Noah A, Adrians N, Everson E, Hess S, Hill C, et al. Clients' perspectives on therapy termination. Psychother Res. 2011;21:154-67.

29. Lilliengen P, Werbart A. Therapists' view of therapeutic action in psychoanalytic psychotherapy with young adults. Psychotherapy (Chic). 2010;47:570-85.

30. Lilliengren $P$, Werbart A. A Model of therapeutic action grounded in the patients' view of curative and hindering factors in psychoanalytic psychotherapy. Psychotherapy (Chic). 2005;42:324-39.

31. Gabbard GO. Introduction. In: Levy RA, Ablon JS, editors. Handbook of evidence-based psychodynamic psychotherapy. New York: Humana; 2009. p. 25-33.

32. Jung S, Nunes MLT, Eizirik CL. Avaliação de resultados da psicoterapia psicanalítica. Rev Psiquiatr Rio Gd Sul. 2007;29:184-96.

33. Denzin NK, Lincoln YS. Handbook of qualitative research. Thousand Oaks: Sage Publications; 1994.

34. Bardin L. Análise de conteúdo. Lisboa: Edições 70; 1995.

35. Kessler RC, Berglund P, Demler O, Jin R, Koretz D, Merikangas $K R$, et al. The epidemiology of major depressive disorder: results from the National Comorbidity Survey Replication (NCS-R). JAMA. 2003;289:3095-105.

36. Montado G. Psicoterapia focal psicoanalítica: investigación de proceso y resultados. In: Bernardi R, editor. Psicoanálisis focos y aperturas. Montevideo: Ágora/Psicolibros; 2001. p. 248-61.

37. Safren SA, Heimberg RG, Juster HR. Clients' expectancies and their relationship to pretreatment symptomatology and outcome of cognitive-behavioral group treatment for social phobia. J Consult Clin Psychol.1997;65:694-8.

38. Bosch MF. Doing psychotherapy. New York: Basic Books; 1980.

39. Ceitlin LH, Cordioli AV. O início da psicoterapia. In: Cordioli AV, editor. Psicoterapia abordagens atuais. Porto Alegre: Artmed; 2008. p. 125-37.

40. Cordioli AV, Gomes F. As condições do paciente e a escolha da terapia. In: Cordioli AV, editor. Psicoterapias abordagens atuais. Porto Alegre: Artmed; 2008. p. 103-24.

41. Krause M, De la Parra G, Arístegui R, Dagnino P, Tomicic A, Valdés $\mathrm{N}$, et al. The evolution of therapeutic change studied through generic change indicators. Psychother Res. 2007;17:673-89.

42. Delsignore A, Schnyder U. Control expectancies as predictors of psychotherapy outcome: a systematic review. $\mathrm{Br}$ J Clin Psychol. 2007;46:467-83.

43. Pfingsten $U$, Hinsch R. Prediction of therapeutic effects of a social skills training in groups. In: Minsel W, Herff W, editors. Proceedings of the First European Conference on Psychotherapy Research. Frankfurt: Lang; 1982. p. 204-9.

44. Gabbard GO. Elaboração e término. In: Gabbard GO, editor. Psicoterapia psicodinâmica de longo prazo: texto básico. Porto Alegre: ArtMed; 2005. p. 161-78.
45.Caligor E, Kernberg O, Clarkin J. Psicoterapia dinâmica das patologias leves da Personalidade. Porto Alegre: Artmed; 2008.

46. Zimerman DE. Fundamentos psicanalíticos. Porto Alegre: Artmed; 1999.

47. Nilsson $T$, Svensson $M$, Sandell $R$, Clinton D. Patients' experiences of change in cognitive behavioral therapy and psychodynamic therapy: a qualitative comparative study. Psychother Res. 2007;17:5533-66.

48. Tryon GS, Kane AS. Relationship of working alliance to mutual and unilateral termination. J Counsel Psychol. 1993;40:33-6.

49. Freud S. Dinâmica da transferência (1912). In: Edição standard brasileira das obras psicológicas completas de Sigmund Freud. Rio de Janeiro: Imago; 1989. p. 131-43.

50. Friedman L. A reading of Freud's papers on technique. Psychoanal Q. 1991;60:564-95.

51. Swift JK, Callahan JL. A delay discounting measure of great expectations and the effectiveness of psychotherapy. Prof Psychol Res Pr. 2008;39:581-88.

52. Leuzinger-Bohleber $M$, Stuhr $U$, Ruge $B$, Beutel $M$. How to study the quality of psychoanalytic treatments and their longterm effects on patients' well-being: a representative, multiperspective followup study. Int J Psychoanal. 2003;84:263-90.

53. Barbato A, D'Avanzo, B. Efficacy of couple therapy as a treatment for depression: a meta-analysis. Psychiat Quart. 2008; 79:121-32.

54. Todd DM, Deane FP, Bragdon RA. Client and therapist reasons for termination: a conceptualization and preliminary validation. J Clin Psychol. 2003;59:133-47.

55. Westmacott R, Hunsley J. Reasons for terminating psychotherapy: a general population study. J Clin Psychol. 2010;66:965-77.

56. Roe D, Dekel R, Harel G, Fennig S. Clients' reasons for terminating psychotherapy: a quantitative and qualitative inquiry. Psychol Psychother. 2006;79:529-38.

57. Vargas F, Nunes ML. Razões expressas para o abandono de tratamento psicoterápico. Aletheia. 2003;17:155-8.

58. Coutinho J, Ribeiro E, Hill C, Safran J. Therapists' and clients' experiences of alliance ruptures: a qualitative study. Psychother Res. 2011;21:525-40.

59. Thomä $H$, Kächele $H$. A entrevista inicial e os terceiros na aliança. In: Thomä $H$, Kächele $H$. Teoria e prática da psicanálise: fundamentos teóricos. Porto Alegre: Artmed; 1992. p. 185-230.

60. Freud S. Sobre o início do tratamento (1912). In: Edição standard brasileira das obras psicológicas completas de Sigmund Freud. Rio de Janeiro: Imago; 1989. p. 163-87.

61. Serralta FS, Pole N, Tiellet Nunes ML, Eizirik CL, Olsen C. The process of change in brief psychotherapy: effects of psychodynamic and cognitive-behavioral prototypes. Psychother Res. 2010;20:564-75.

62. Castonguay LG, Goldfried Mr, Wiser S, Raue PJ, Hayes AM. Predicting effects of cognitive therapy for depression. A study of unique and common factors. J Consult Clin Psychol. 1996;64:497-504.

63. Jung SI. É possível fazer pesquisa de resultados em psicoterapia psicanalítica? Bol Inf Estud Integr Psicoter Psicanal. 2004; 7:6.

\section{Correspondence}

Simone Isabel Jung

Rua Emílio Lúcio Esteves, 1187/303

95600000 - Taquara, RS - Brazil

E-mail: simoneisabeljung@gmail.com 


\section{Trends}

The authors of the article entitled "Beginning and end of treatment of patients who dropped out of psychoanalytic psychotherapy" (Simone Isabel Jung, Fernanda Barcellos Serralta, Maria Lucia Tiellet Nunes, Cláudio Laks Eizirik) identified an error in the version published. On page 187, first column, end of the third new paragraph, "was presented only by P2 and P6" should read "was presented only by P2 and P3." 